\title{
The reversibility of sea ice loss in a state-of-the-art climate model
}

\author{
K. C. Armour, ${ }^{1}$ I. Eisenman, ${ }^{2,3}$ E. Blanchard-Wrigglesworth, ${ }^{3}$ K. E. McCusker, ${ }^{3}$ \\ and C. M. Bitz ${ }^{3}$ \\ Received 29 June 2011; accepted 15 July 2011; published 20 August 2011.
}

[1] Rapid Arctic sea ice retreat has fueled speculation about the possibility of threshold (or 'tipping point') behavior and irreversible loss of the sea ice cover. We test sea ice reversibility within a state-of-the-art atmosphereocean global climate model by increasing atmospheric carbon dioxide until the Arctic Ocean becomes ice-free throughout the year and subsequently decreasing it until the initial ice cover returns. Evidence for irreversibility in the form of hysteresis outside the envelope of natural variability is explored for the loss of summer and winter ice in both hemispheres. We find no evidence of irreversibility or multiple ice-cover states over the full range of simulated sea ice conditions between the modern climate and that with an annually ice-free Arctic Ocean. Summer sea ice area recovers as hemispheric temperature cools along a trajectory that is indistinguishable from the trajectory of summer sea ice loss, while the recovery of winter ice area appears to be slowed due to the long response times of the ocean near the modern winter ice edge. The results are discussed in the context of previous studies that assess the plausibility of sea ice tipping points by other methods. The findings serve as evidence against the existence of threshold behavior in the summer or winter ice cover in either hemisphere. Citation: Armour, K. C., I. Eisenman, E. Blanchard-Wrigglesworth, K. E. McCusker, and C. M. Bitz (2011), The reversibility of sea ice loss in a stateof-the-art climate model, Geophys. Res. Lett., 38, L16705, doi:10.1029/2011GL048739.

\section{Introduction}

[2] Arctic sea ice has undergone rapid changes in recent decades. Observations showing substantial reduction in areal sea ice coverage [Meier et al., 2006; Stroeve et al., 2007] and overall thinning in conjunction with a loss of older, thicker sea ice [Maslanik et al., 2007; Kwok et al., 2009] have fueled speculation that Arctic sea ice may be at or near a critical threshold (or 'tipping point'), beyond which abrupt and irreversible loss of ice will occur [e.g., Lindsay and Zhang, 2005; Overpeck et al., 2005; Serreze and Francis, 2006; Kerr, 2007; Serreze et al., 2007; Maslanik et al., 2007; Lenton and Schellnhuber, 2007; Serreze and Stroeve, 2008; Lenton et al., 2008; Ramanathan and Feng, 2008].

\footnotetext{
${ }^{1}$ Department of Physics, University of Washington, Seattle, Washington, USA.

${ }^{2}$ Geological and Planetary Sciences, California Institute of Technology, Pasadena, California, USA.

${ }^{3}$ Department of Atmospheric Sciences, University of Washington, Seattle, Washington, USA.

Copyright 2011 by the American Geophysical Union. 0094-8276/11/2011GL048739
}

[3] Does the sea ice system show hallmarks of threshold behavior, such as multiple ice-cover states and hysteresis? Direct assessment of sea ice reversibility with theory [Eisenman and Wettlaufer, 2009] and indirect assessments with coupled atmosphere-ocean global climate models (GCMs) [e.g., Winton, 2006, 2008; Ridley et al., 2008; Amstrup et al., 2010; Tietsche et al., 2011] indicate that a tipping point in summer Arctic sea ice cover is unlikely. However, direct assessments within GCMs have yet to be performed. Such a measure could be achieved by looking for hysteresis in sea ice cover when radiative forcing is raised until the oceans become ice-free and subsequently lowered, ideally within a suite of different state-of-the-art coupled GCMs.

[4] This work represents a step toward this goal: we report the results of a simulation with a state-of-the-art coupled GCM in which atmospheric $\mathrm{CO}_{2}$ is increased at $1 \% \mathrm{yr}^{-1}$ (compounded) until the Arctic Ocean becomes ice-free throughout the year and subsequently decreased until the initial ice cover returns. Evidence for sea ice irreversibility in the form of hysteresis outside the envelope of year-toyear variability is examined for the loss of summer and winter ice cover in both hemispheres.

\section{Methods}

[5] We use version 3 of the Community Climate System Model (CCSM3) at the standard resolution, which is T42 spectral truncation in the atmosphere and a nominally $1^{\circ}$ ocean grid [Collins et al., 2006]. Sea ice conditions in CCSM3 are well described previously [e.g., Holland et al., 2006a, 2006b]. The Arctic sea ice cover in this model is the most sensitive to climate changes of the current suite of state-of-the-art GCMs [Stroeve et al., 2007; Winton, 2011; Eisenman et al., 2011], and it has been found to exhibit rapid changes, comparable to recent observations [Holland et al., 2006a], which have been interpreted as evidence for irreversible tipping points [e.g., Serreze et al., 2007; Serreze and Stroeve, 2008]. Our simulation branches from a modernday (1990s) control run with initial $\mathrm{CO}_{2}$ concentration of 355 ppmv. Carbon dioxide is ramped at $+1 \% \mathrm{yr}^{-1}$ until the Northern Hemisphere $(\mathrm{NH})$ becomes perennially ice-free (monthly sea ice area consistently less than $10^{6} \mathrm{~km}^{2}$ ). This occurs in year 219 of ramping, at which point $\mathrm{CO}_{2}$ is approximately nine times its initial level and the globalmean surface temperature has increased by about $6.5^{\circ} \mathrm{C}$ (red points in Figure 1). While the Southern Hemisphere ( $\mathrm{SH}$ ) becomes ice-free in austral summer, its winter ice cover persists throughout the ramping. Upon reaching an ice-free Arctic, $\mathrm{CO}_{2}$ is decreased at $-1 \% \mathrm{yr}^{-1}$ until both hemispheres are returned to near their initial (1990s) temperatures (blue points in Figure 1), which occurs in year 493 of the simulation when $\mathrm{CO}_{2}$ is around 205 ppmv. 

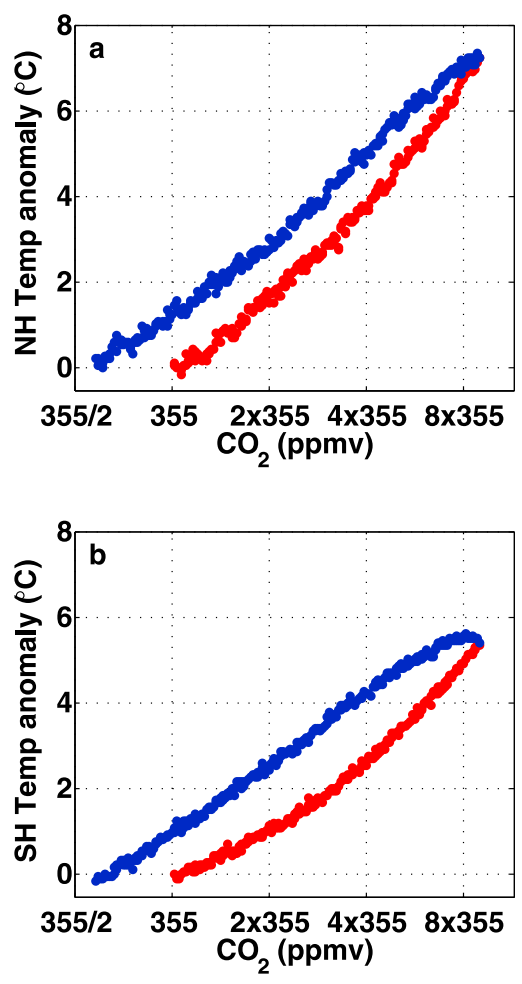

Figure 1. (a) NH-mean and (b) SH-mean annual-mean surface temperature anomalies as a function of atmospheric $\mathrm{CO}_{2}$ concentration in the CCSM3 simulation. Increasing $\mathrm{CO}_{2}$ concentration (in red) results in a warming trajectory and decreasing $\mathrm{CO}_{2}$ concentration (in blue) results in a cooling trajectory. Temperature anomalies are with respect to the 1990 control level, and $\mathrm{CO}_{2}$ is plotted on a log scale.

[6] Global radiative forcing $(F)$ changes approximately linearly with time over the $\mathrm{CO}_{2}$ rampings, by about $3.7 \mathrm{Wm}^{-2}$ per $70 \mathrm{yr}$, which is the period of $\mathrm{CO}_{2}$ doubling or halving [Myhre et al., 1998]. The offset in Figure 1 between warming (red) and cooling (blue) trajectories implies a lagged response of hemispheric-mean annual-mean surface temperature anomalies $\left(\Delta T_{\mathrm{NH}}\right.$ and $\left.\Delta T_{\mathrm{SH}}\right)$, as expected from deep ocean heat storage [e.g., Held et al., 2010]. In order to approximately account for this lag, we consider the evolution of ice area as a function of hemispheric temperature rather than time. A justification for this treatment is that annual-mean Arctic sea ice area has been found to decline linearly with increasing global-mean temperature across a range of GCMs, emissions scenarios, and climates [Gregory et al., 2002; Ridley et al., 2008; Winton, 2006, 2008, 2011]. Specifically, we extend the arguments of Winton [2011], relating hemispheric ice cover to global forcing through

$$
\Delta A_{\mathrm{NH}}=\frac{\Delta A_{\mathrm{NH}}}{\Delta T_{\mathrm{NH}}} \frac{\Delta T_{\mathrm{NH}}}{\Delta F} \Delta F,
$$

and

$$
\Delta A_{\mathrm{SH}}=\frac{\Delta A_{\mathrm{SH}}}{\Delta T_{\mathrm{SH}}} \frac{\Delta T_{\mathrm{SH}}}{\Delta F} \Delta F,
$$

where $A_{\mathrm{NH}}$ and $A_{\mathrm{SH}}$ are monthly- or annual-mean hemispheric ice areas. We define $\Delta A_{\mathrm{NH}} / \Delta T_{\mathrm{NH}}$ and $\Delta A_{\mathrm{SH}} / \Delta T_{\mathrm{SH}}$ as the sea ice sensitivity in each hemisphere, which is similar to the treatment by Winton [2011] except that we consider both hemispheres and use hemispheric-mean rather than global-mean temperature.

[7] Separating the dependence of temperature on forcing $\left(\Delta T_{\mathrm{NH}} / \Delta F\right.$ and $\left.\Delta T_{\mathrm{SH}} / \Delta F\right)$ from the dependence of ice area on temperature $\left(\Delta A_{\mathrm{NH}} / \Delta T_{\mathrm{NH}}\right.$ and $\left.\Delta A_{\mathrm{SH}} / \Delta T_{\mathrm{SH}}\right)$ permits a consistent comparison of sea ice sensitivity across climate models and forcing scenarios [Winton, 2011], accounts for contrasting hemispheric climate trends (Figure 1), and effectively isolates the sea ice response to hemispheric climate change for the purposes of evaluating sea ice reversibility (see Figure $\mathrm{S} 1$ in the auxiliary material for an alternative approach that relates $\Delta A_{\mathrm{NH}}$ and $\Delta A_{\mathrm{SH}}$ directly to $\Delta F$ with a specified memory timescale). ${ }^{1}$ For the remainder of this analysis we examine the evidence for hysteresis in hemispheric ice area with respect to hemispheric-mean annual-mean temperature ( $\Delta A_{\mathrm{NH}}$ vs $\Delta T_{\mathrm{NH}}$ and $\Delta A_{\mathrm{SH}}$ vs $\left.\Delta T_{\mathrm{SH}}\right)$.

\section{Reversibility of Sea Ice Loss}

[8] We first describe the progression to an ice-free Arctic under $\mathrm{NH}$ warming (red points in Figures $2 \mathrm{a}-2 \mathrm{c}$ ). The strong linearity of annual-mean ice area decline continues throughout the simulation, spanning a range in $T_{\mathrm{NH}}$ of over $6^{\circ} \mathrm{C}$ (Figure 2a). However, the trajectories of monthly ice cover (Figures $2 \mathrm{~b}$ and $2 \mathrm{c}$ ) show more complex behavior. A large change in March ice cover sensitivity occurs when ice area is approximately equal to that of the Arctic basin $(\sim 9 \times$ $10^{6} \mathrm{~km}^{2}$ ), suggestive of geographic controls on the rate of area loss with warming [Eisenman, 2010]. Indeed, the March "equivalent ice area" as defined by Eisenman [2010], which accounts for geographic effects, is found to vary linearly with $T_{\mathrm{NH}}$ over the entire range (Figure S2). Note that the observed relationship between $A_{\mathrm{NH}}$ and $T_{\mathrm{NH}}$ for 1979-2010 (black points in Figures 2a-2c) demonstrates model biases in both the mean state [cf. Holland et al., 2006b] and sensitivity [cf. Winton, 2011] of the sea ice cover simulated with CCSM3.

[9] The relationship between warming (red) and cooling (blue) trajectories in Figure 2 illustrates the reversibility of sea ice area loss. Subject to NH cooling, September ice area recovers along a trajectory that is visually indistinguishable from the warming trajectory (Figure $2 b$ ). Thus these results suggest that the loss of September Arctic ice cover within CCSM3 is fully reversible over the range of sea ice states between modern and annually ice-free climates.

[10] March ice area, by contrast, recovers along a trajectory that is increasingly distinct from the warming trajectory when the sea ice edge extends beyond the Arctic basin $\left(A_{\mathrm{NH}}\right.$ $\gtrsim 9 \times 10^{6} \mathrm{~km}^{2}$ in Figure $2 \mathrm{c}$ ). This may initially seem to suggest the possibility of hysteresis and hence multiple stable ice-cover states under the same hemispheric-mean temperature. However, comparison between the spatial patterns of March ice cover and annual-mean surface temperature under warming and cooling reveals distinct locations, including the Sea of Okhotsk, where March ice area recovery is substantially delayed (Figure 3a). These locations largely correspond to regions of the ocean that have

${ }^{1}$ Auxiliary materials are available in the HTML. doi:10.1029/ 2011GL048739. 

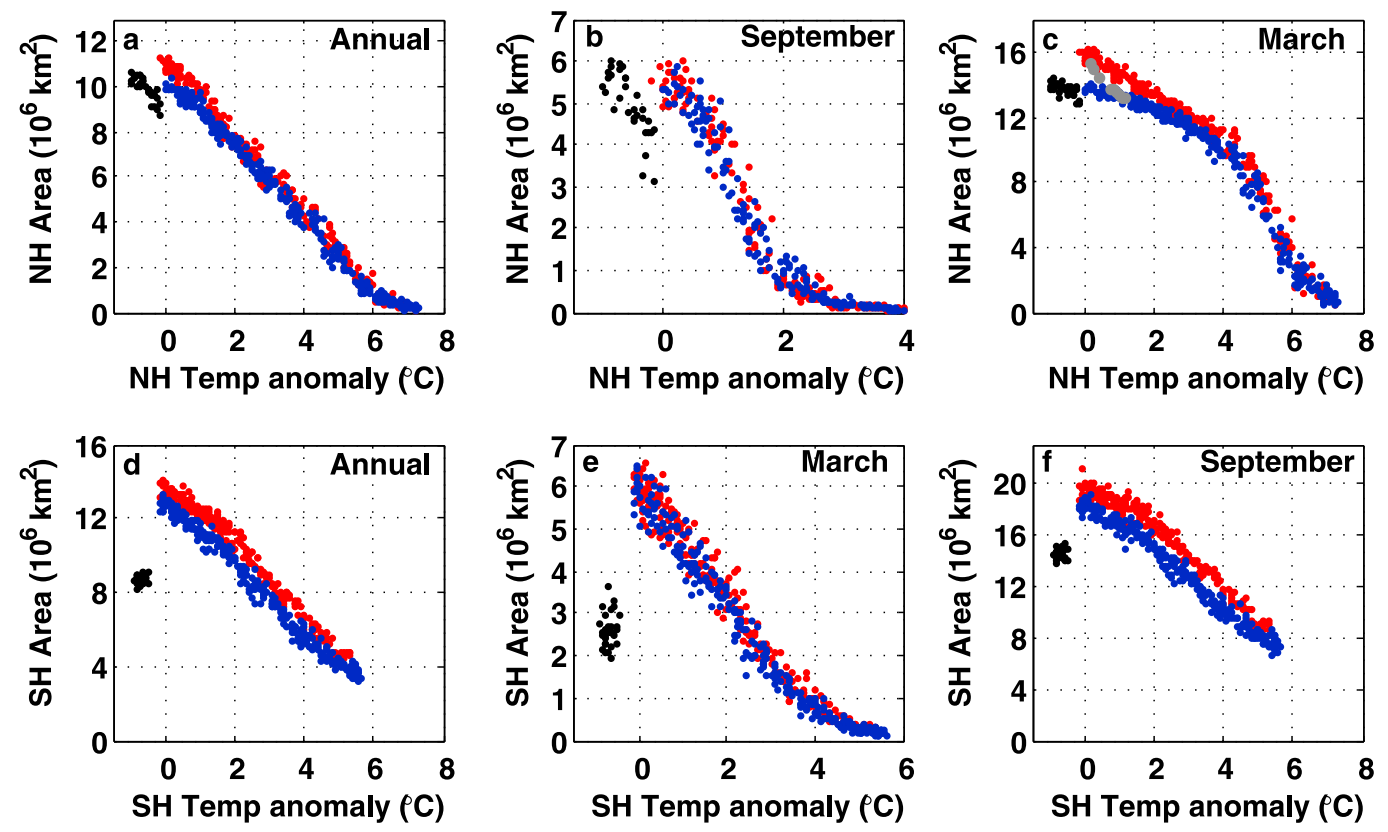

Figure 2. Hemispheric sea ice area as a function of hemispheric-mean annual-mean surface temperature anomaly. (top) Arctic sea ice (a) annual-mean area, (b) September area, and (c) March area. (bottom) Antarctic sea ice (d) annual-mean area, (e) March area, and (f) September area. The use of red and blue is as described in Figure 1. Black points show the observed relationship between ice area [Meier et al., 2006] and temperature anomalies [Hansen et al., 2010] for the period 1979-2010. Observed temperatures have been normalized to CCSM3 for the period 1950-1980 of a 20th Century CCSM3 simulation. Gray points in Figure 2c show 50-year averages of an additional 450-year long simulation in which $\mathrm{CO}_{2}$ is held fixed upon returning to the initial concentration of $355 \mathrm{ppmv}$, instead of continuing to decrease at $-1 \% \mathrm{yr}^{-1}$ to $205 \mathrm{ppmv}$ as in the blue trajectory.

been previously noted to exhibit extremely long timescales of response to climate forcing, particularly when cooling [Stouffer, 2004]. Thus, it is likely that the difference between warming and cooling trajectories is due to spatially varying timescales of adjustment, and is an artifact of the relatively fast rate of $\mathrm{CO}_{2}$ variation in our simulation.

[11] To verify this interpretation, we examine an additional 450-year long simulation in which $\mathrm{CO}_{2}$ is held fixed after reaching the initial value of 355 ppmv during the ramp down (gray points in Figure 2c). If multiple ice-cover states were supported by the same $T_{\mathrm{NH}}$, then the ice area would be expected to remain constant or continue to evolve along the cooling trajectory in $A_{\mathrm{NH}}$ vs $T_{\mathrm{NH}}$ space. Instead, the ice cover evolves toward its initial (1990s) state as the anomalously warm regions of the ocean slowly attain equilibrium (cf. Figure 3). We thus conclude that March ice area shows no signs of hysteresis, and that the loss of the modern Arctic wintertime sea ice cover appears to be reversible within CCSM3.

[12] We note that even when the March ice edge is within the Arctic basin $\left(A_{\mathrm{NH}} \lesssim 9 \times 10^{6} \mathrm{~km}^{2}\right)$, there is a small offset between the warming and cooling trajectories which can be seen under close inspection of Figure 2c. However, the offset appears to be relatively constant and hence consistent with a small difference in lag between $T_{\mathrm{NH}}$ and $A_{\mathrm{NH}}$, rather than a hysteresis window, and it does not occur when a memory timescale is explicitly imposed (Figure S1).

[13] The Antarctic sea ice sensitivity in CCSM3 is very similar to the Arctic sea ice sensitivity, as illustrated by the similar slopes in Figures $2 \mathrm{a}$ and $2 \mathrm{~d}$ [cf. Eisenman et al., 2011]. The SH reaches ice-free conditions in late austral summer (March) during the warming trajectory (Figure 2e), but in contrast to the NH, late austral winter (September) ice cover never disappears completely (Figure 2f). This is associated with a smaller increase in $T_{\mathrm{SH}}$ than in $T_{\mathrm{NH}}$. Note that there is a substantial positive bias in current $A_{\mathrm{SH}}$ in CCSM3 compared with observations. Acknowledging this, we assess the evidence for Antarctic sea ice irreversibility and compare with the NH results.

[14] Subject to $\mathrm{SH}$ cooling, March ice area recovers along a trajectory that is visually indistinguishable from the warming trajectory (Figure 2e), and thus appears to be fully reversible over the range of sea ice states between modern and ice-free climates. The recovery of September ice area, by contrast, occurs along a cooling trajectory that is distinct from the warming trajectory (Figure 2f). However, like NH winter sea ice when it is contained within the Arctic basin, the cooling trajectory appears to simply be lagged behind the warming trajectory, consistent with the relatively slow response of distinct locations in the Southern Ocean (Figure 3b). Thus, the loss of Antarctic winter ice cover appears to be reversible within CCSM3.

\section{Discussion and Conclusions}

[15] The central finding of this study is that sea ice loss is fully reversible in a state-of-the-art GCM over a range of $\mathrm{CO}_{2}$ concentrations from the 1990s level to nine times higher. We find no evidence for threshold behavior in the summer or winter ice cover in either hemisphere. Thus if tipping points exist for future sea ice retreat in nature, it is for subtle reasons, i.e., through processes that are absent or 

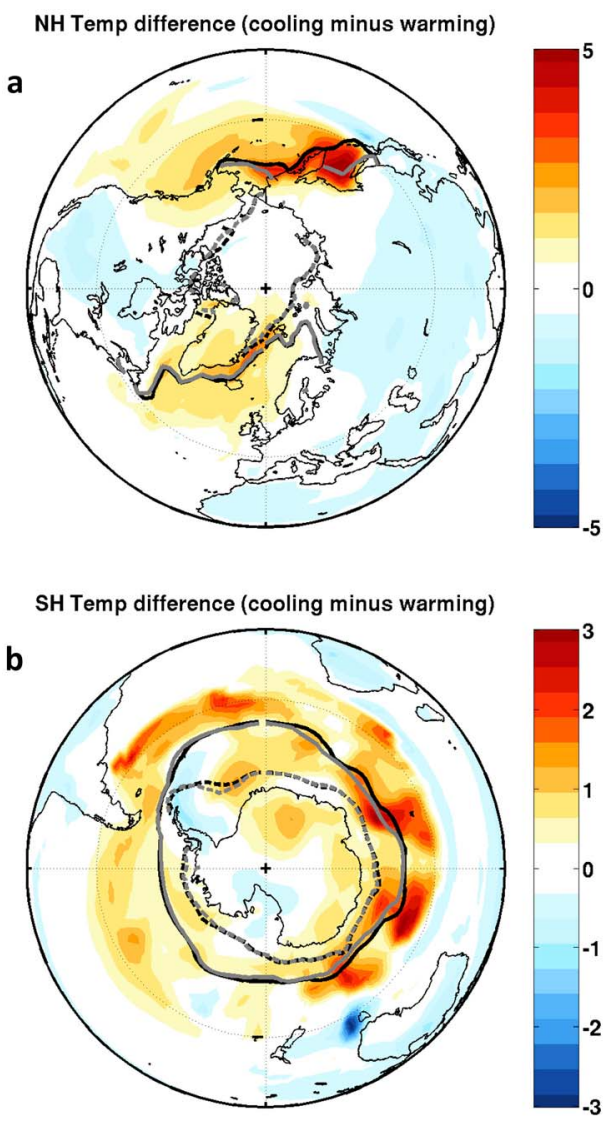

Figure 3. (a) $\mathrm{NH}$ and (b) $\mathrm{SH}$ annual-mean surface temperature anomaly $\left({ }^{\circ} \mathrm{C}\right)$ and sea ice extent differences between cooling and warming trajectories, averaged over 30-year periods when hemispheric-mean temperature is comparable (years 30-60 compared to years 437-467). Thick lines show $15 \%$ sea ice concentration contours, with black corresponding to the warming trajectory, gray corresponding to the cooling trajectory, solid lines showing winter sea ice extent, and dashed lines showing summer ice extent.

inadequately represented in this model. Our results do not address the possibility of sea ice hysteresis between closely separated states within the envelope of natural variability or in climate regimes with more extensive ice cover [e.g., Marotzke and Botzet, 2007; Rose and Marshall, 2009].

[16] These findings can be compared with previous studies. Winton [2006] finds that CCSM3 loses all of its Arctic sea ice in a linear manner, consistent with our results, and that another GCM considered (MPI ECHAM5) also loses its summer ice cover linearly. Tietsche et al. [2011] similarly find no evidence of summer Arctic sea ice tipping points in the ECHAM5 model. However, Winton [2006] finds that ECHAM5 shows evidence for nonlinearity during the loss of its winter Arctic ice cover. Eisenman and Wettlaufer [2009] propose a physical argument that if an irreversible threshold exists for the sea ice cover, it should be expected during the loss of winter ice. It thus seems plausible that some models, such as ECHAM5, may show irreversible threshold behavior during the loss of winter ice cover in a very warm climate, in contrast to the CCSM3 results presented here. This emphasizes the importance of repeating $\mathrm{CO}_{2}$ ramping experiments such as this one with other state-of-the-art coupled GCMs.
[17] Summer sea ice cover in each hemisphere appears to have a well-defined relationship with hemispheric-mean temperature, under both warming and cooling trajectories, suggesting the possibility of relatively simple thermodynamic controls on summer ice cover. Winter sea ice cover also appears to be related to hemispheric-mean temperature, but its rate of loss and recovery is found to be complicated by the local response of the oceans near the winter ice edge.

[18] A lack of hysteresis in sea ice area may be expected based on the short persistence timescale of ice area anomalies, as found in both models [Holland et al., 2010; Blanchard-Wrigglesworth et al., 2011; Tietsche et al., 2011] and observations [e.g., Eisenman, 2010; BlanchardWrigglesworth et al., 2011]. The short timescale means that sea ice area responds to climate changes on timescales of a few years or less and, thus, responds to slow climate variations independently of its history (i.e., without hysteresis) [Gregory et al., 2002; Armour et al., 2011]. Alternatively, other components of the climate system (e.g., ocean circulation) could plausibly be expected to exhibit hysteretic behavior and, in turn, drive sea ice irreversibility, but such a scenario did not occur within our simulation.

[19] Components of the climate system not represented in CCSM3 (e.g., dynamic land ice) could, in principle, cause sea ice hysteresis. Similarly, the simulation setup in this study does not address the possibility of hysteresis when $\mathrm{CO}_{2}$ is varied more slowly such that the deep ocean temperature is near steady-state with the forcing. Thus, our findings are expected to be most relevant to the assessment of sea ice thresholds under transient warming over the next few centuries in the absence of substantial land ice sheet changes.

[20] A recent analysis of Held et al. [2010] suggests that the climate system can be viewed as comprising a fast upper ocean component with a characteristic timescale of $<5$ years and a slowly evolving deep ocean component. In this view, the surface component is driven by a mixture of radiative forcing and exchange with the more slowly evolving deep ocean, which leads to the difference between warming and cooling surface temperature trajectories under the same radiative forcing in Figure 1. Hence the source of the several decade time lags in Figure S1 may be primarily due to forcing of the surface component by heat exchange with the deep ocean. Due to the rate of radiative forcing changes in the simulation presented here, our results do not address the possibility of hysteresis in deep ocean temperature, but they suggest that there is not hysteresis in the surface climate. An implication of this interpretation is that reduced forcing after modest warming would result in a quick return to initial sea ice conditions, whereas if deep ocean warming is maintained for centennial timescales (as in the scenario presented here), the recovery of the sea ice cover would be substantially delayed even under abrupt reductions in greenhouse gas forcing.

[21] The results presented here illustrate a hazard of using factors such as an increase in variance as generic 'earlywarning signals' of an approaching tipping point [e.g., Lenton and Schellnhuber, 2007; Lenton et al., 2008; Scheffer et al., 2009]. Although we find that CCSM3 does not show evidence of a summer sea ice tipping point, the variance in summer Arctic sea ice area increases in the model as the climate warms [Holland et al., 2008; Goosse et al., 2009]. The increase in variance may plausibly be 
related to a reduction in stability, or alternatively it may be driven by other factors such as reduced geographic muting of ice edge variability [Goosse et al., 2009; Eisenman, 2010] or an overall thinning of the ice pack [Notz, 2009]. However, in light of the present findings, it does not appear to be associated with a loss of stability altogether. Given that these same processes are expected to be at work in nature, variance in the observed sea ice cover may similarly be an unreliable indicator of an approaching threshold.

[22] Finally, the coupled GCM that we employ in this study (CCSM3) exhibits periods of rapid sea ice loss under warming [Holland et al., 2006a]-comparable to recent observations - that have often been interpreted as tipping point behavior [e.g., Serreze et al., 2007; Serreze and Stroeve, 2008]. However, the reversibility of the sea ice cover within this model suggests that such interpretations are misguided. The lack of evidence for critical sea ice thresholds within a state-of-the-art GCM implies that future sea ice loss will occur only insofar as global warming continues, and may be fully reversible. This is ultimately an encouraging conclusion; although some future warming is inevitable [e.g., Armour and Roe, 2011], in the event that greenhouse gas emissions are reduced sufficiently for the climate to cool back to modern hemispheric-mean temperatures, a sea ice cover similar to modern-day is expected to follow.

[23] Acknowledgments. We gratefully acknowledge support from National Science Foundation grants OCE-0256011 and ARC-0909313, the Davidow Discovery Fund, and a NOAA Climate and Global Change Postdoctoral Fellowship to IE administered by the University Corporation for Atmospheric Research. We thank Dorian Abbot, Gerard Roe, Brian Rose and Michael Winton for valuable discussions, and Eric Rignot, the editor.

[24] The Editor thanks an anonymous reviewer for his assistance in evaluating this paper.

\section{References}

Amstrup, S. C., et al. (2010), Greenhouse gas mitigation can reduce sea-ice loss and increase polar bear persistence, Nature, 468, 955-958.

Armour, K. C., and G. H. Roe (2011), Climate commitment in an uncertain world, Geophys. Res. Lett., 38, L01707, doi:10.1029/2010GL045850.

Armour, K. C., et al. (2011), Controls on Arctic sea ice from first-year and multiyear ice survivability, J. Clim., 24, 2378-2390.

Blanchard-Wrigglesworth, E., et al. (2011), Persistence and inherent predictability of Arctic sea ice in a GCM ensemble and observations, $J$. Clim., 24, 231-250.

Collins, W. D., et al. (2006), The Community Climate System Model: CCSM3, J. Clim., 19, 2122-2143.

Eisenman, I. (2010), Geographic muting of changes in the Arctic sea ice cover, Geophys. Res. Lett., 37, L16501, doi:10.1029/2010GL043741.

Eisenman, I., and J. S. Wettlaufer (2009), Nonlinear threshold behavior during the loss of Arctic sea ice, Proc. Natl. Acad. Sci. U. S. A., 106, $28-32$.

Eisenman, I., et al. (2011), Consistent changes in the sea ice seasonal cycle in response to global warming, J. Clim., in press.

Goosse, H., O. Arzel, C. M. Bitz, A. de Montety, and M. Vancoppenolle (2009), Increased variability of the Arctic summer ice extent in a warmer climate, Geophys. Res. Lett., 36, L23702, doi:10.1029/2009GL040546.

Gregory, J. M., P. A. Stott, D. J. Cresswell, N. A. Rayner, C. Gordon, and D. M. H. Sexton (2002), Recent and future changes in Arctic sea ice simulated by the HadCM3 AOGCM, Geophys. Res. Lett., 29(24), 2175, doi:10.1029/2001GL014575.

Hansen, J., R. Ruedy, M. Sato, and K. Lo (2010), Global surface temperature change, Rev. Geophys., 48, RG4004, doi:10.1029/2010RG000345.

Held, I. M., et al. (2010), Probing the fast and slow components of global warming by returning abruptly to pre-industrial forcing, J. Clim., 23, $2418-2427$.

Holland, M. M., C. M. Bitz, and B. Tremblay (2006a), Future abrupt reductions in the summer Arctic sea ice, Geophys. Res. Lett., 33, L23503, doi:10.1029/2006GL028024.
Holland, M. M., et al. (2006b), Influence of the sea ice thickness distribution on polar climate in CCSM3, J. Clim., 19, 2398-2414.

Holland, M. M., et al. (2008), The role of natural versus forced change in future rapid summer Arctic ice loss, in Arctic Sea Ice Decline: Observations, Projections, Mechanisms, and Implications, Geophys. Monogr. Ser., vol. 180, edited by E. DeWeaver, C. M. Bitz, and B. Tremblay, pp. 133-150, AGU, Washington, D. C.

Holland, M. M., et al. (2010), Inherent sea ice predictability in the rapidly changing Arctic environment of the Community Climate System Model, version 3, Clim. Dyn., 36, 1239-1253.

Kerr, R. A. (2007), Is battered Arctic sea ice down for the count?, Science, 318, 33-34.

Kwok, R., G. F. Cunningham, M. Wensnahan, I. Rigor, H. J. Zwally, and D. Yi (2009), Thinning and volume loss of the Arctic Ocean sea ice cover: 2003-2008, J. Geophys. Res., 114, C07005, doi:10.1029/ 2009JC005312.

Lenton, T. M., and H. J. Schellnhuber (2007), Tipping the scales, Nat. Rep. Clim. Change, 1, 97-98.

Lenton, T. M., et al. (2008), Tipping elements in the Earth's climate system, Proc. Natl. Acad. Sci. U. S. A., 105, 1786-1793.

Lindsay, R. W., and J. Zhang (2005), The thinning of arctic sea ice, 1988-2003: Have we passed a tipping point?, J. Clim., 18, 4879-4894. Marotzke, J., and M. Botzet (2007), Present-day and ice-covered equilibrium states in a comprehensive climate model, Geophys. Res. Lett., 34, L16704, doi:10.1029/2006GL028880.

Maslanik, J. A., C. Fowler, J. Stroeve, S. Drobot, J. Zwally, D. Yi, and W. Emery (2007), A younger, thinner Arctic ice cover: Increased potential for rapid, extensive sea-ice loss, Geophys. Res. Lett., 34, L24501, doi:10.1029/2007GL032043.

Meier, W., et al. (2006), Sea ice concentrations from Nimbus-7 SMMR and DMSP SSM/I passive microwave data, 1979-2010, digital media, Natl. Snow and Ice Data Cent., Boulder, Colo.

Myhre, G., E. J. Highwood, K. P. Shine, and F. Stordal (1998), New estimates of radiative forcing due to well mixed greenhouse gases, Geophys. Res. Lett., 25, 2715-2718.

Notz, D. (2009), The future of ice sheets and sea ice: Between reversible retreat and unstoppable loss, Proc. Natl. Acad. Sci. U. S. A., 106, 20,590-20,595.

Overpeck, J. T., et al. (2005), Arctic system on trajectory to new, seasonally ice-free state, Eos Trans. AGU, 86(34), doi:10.1029/2005EO340001.

Ramanathan, V., and Y. Feng (2008), On avoiding dangerous anthropogenic interference with the climate system: Formidable challenges ahead, Proc. Natl. Acad. Sci. U. S. A., 38, 14,245-14,250.

Ridley, J., et al. (2008), The demise of Arctic sea ice during stabilisation at high greenhouse gas concentrations, Clim. Dyn., 30, 333-341.

Rose, B. E. J., and J. Marshall (2009), Ocean heat transport, sea ice, and multiple climate states: Insights from energy balance models, J. Atmos. Sci. 66, 2828-2843.

Scheffer, M., et al. (2009), Early-warning signals for critical transitions, Nature, 46, 53-59.

Serreze, M. C., and J. A. Francis (2006), The Arctic amplification debate, Clim. Change, 76, 241-264.

Serreze, M. C., and J. Stroeve (2008), Standing on the brink, Nat. Rep. Clim. Change, 2, 142-143.

Serreze, M. C., et al. (2007), Perspectives on the Arctic's shrinking sea-ice cover, Science, 315, 1533-1536.

Stouffer, R. J. (2004), Time scales of climate response, J. Clim., 17, 209-217.

Stroeve, J., M. M. Holland, W. Meier, T. Scambos, and M. Serreze (2007), Arctic sea ice decline: Faster than forecast, Geophys. Res. Lett., 34, L09501, doi:10.1029/2007GL029703.

Tietsche, S., D. Notz, J. H. Jungclaus, and J. Marotzke (2011), Recovery mechanisms of Arctic summer sea ice, Geophys. Res. Lett., 38 , L02707, doi:10.1029/2010GL045698.

Winton, M. (2006), Does the Arctic sea ice have a tipping point?, Geophys. Res. Lett., 33, L23504, doi:10.1029/2006GL028017.

Winton, M. (2008), Sea ice-albedo feedback and nonlinear Arctic climate change, in Arctic Sea Ice Decline: Observations, Projections, Mechanisms, and Implications, Geophys. Monogr. Ser., vol. 180, edited by E. DeWeaver, C. M. Bitz, and B. Tremblay, pp. 111-131, AGU, Washington, D. C

Winton, M. (2011), Do climate models underestimate the sensitivity of Northern Hemisphere sea ice cover?, J. Clim., in press.

K. C. Armour, Department of Physics, University of Washington, Box 351560, Seattle, WA 98195, USA. (karmour@u.washington.edu)

C. M. Bitz, E. Blanchard-Wrigglesworth, and K. E. McCusker, Department of Atmospheric Sciences, University of Washington, 1013 NE 40th St., Seattle, WA 98105, USA.

I. Eisenman, Geological and Planetary Sciences, California Institute of Technology, Pasadena, CA 91125, USA. 